\title{
Design and Simulation of a Low Voltage Wide Band RF MEMS Switch
}

\author{
Y. Mafinejad, A. Z. Kouzani \\ School of Engineering \\ Deakin University \\ Geelong, VIC 3217, Australia
}

\author{
K. Mafinezhad \\ Dept. of Electrical Engineering \\ Ferdowsi University \\ Mashad, Iran
}

\author{
H. Nabovatti \\ Dept. of Electrical Engineering \\ Sadjad University \\ Mashad, Iran
}

\begin{abstract}
This paper presents design of an electrostatic wide band shunt capacitive coupling RF MEMS switch with low actuation voltage. The key factors of the RF MEMS switch design are the proper scattering parameters, low actuation voltage, and the cost of the fabrication process. An overview of the recent low actuation voltage RFMEMS switches has been presented. These designs still suffer from the complexity of process, lack of reliability, limitation of frequency band, and process cost. RF characteristics of a shunt RF MEMS switches are specified mostly by coupling capacitor in upstate position of the membrane $\mathrm{C}_{\mathrm{u}}$. This capacitor is in trade-off with actuation voltage. In this work, the capacitor is eliminated by using two short high impedance transmission lines, at the input and output of the switch. The simulation results demonstrate an improvement in the RF characteristic of the switch.
\end{abstract}

Keywords-RF MEMS switches, low actuation voltage, piezoelectric actuation, scattering parameters

\section{INTRODUCTION}

Micro electromechanical system (MEMS) can be employed to implement radio frequency (RF) circuits providing such benefits as reduced power dissipation, noise, weight, size and cost. In the past several years, some research activities have been focused on the development of micro electromechanical switches and their applications in RF systems. For example, RF MEMS switches have been used in wireless communications especially in satellite communications and radar systems [1][2][3]. RF MEMS switches offer better performances in comparison with other standard RF switches realised by transistors, PIN diodes, and coaxial cables. This is due to their high electrical isolation, low insertion loss, excellent linearity, ultra wide band frequency, low noise performance, no bias current need (less energy consumption), and ability to integrate with standard IC technologies. However, the RF MEMS switches cannot well handle high power. The power switches are capable of coping with up to several tens watts before device failure [4][5].

There is a great challenge in developing the high performance MEMS switches focusing on power transmission, low actuation voltage, wide band operational frequency, short switching time, good packaging, and high reliability. It is however very hard to implement these performances in a single switch. Nowadays, many researchers try to obtain low actuation voltage for application in commercial wireless communication system by utilising electromagnetic actuation, and lowering spring constant. The most effective way for lowering the actuation voltage is using piezoelectric actuation. Such a switch can achieve low power consumption and high speed switching time. However, the drawback of such a switch is the complexity of its fabrication [6][7].

In this paper, after a brief study of different kinds of MEMS switches, we demonstrate a method to design and simulate the MEMS switches to meet a low actuation voltage and convenient high frequency in $\mathrm{Ka}$ and $\mathrm{V}$ bands.

The paper is organized as follows. Section II gives an overview of some recent RF MEMS switches. Section III describes the proposed RF MEMS switch. Section IV presents the simulation results. Finally, concluding remarks are given in Section V.

\section{OVERVIEW OF SOME EXISTING RF MEMS SWITCHES}

Tauati et al. [8] designed a low voltage actuation switch. In this design, two anchors hold the membrane. A different electrode is placed on each anchor (see Figure 1).

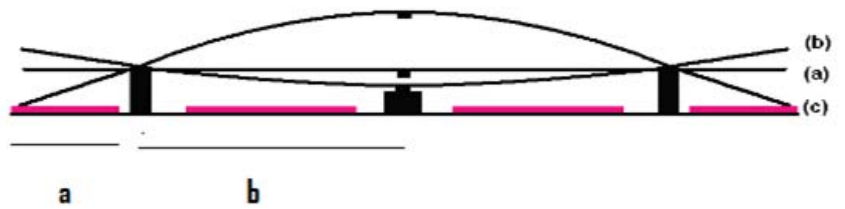

Figure 1. (a) Rest, (b) on, and (c) off state of the membrane in [8].

For the above shunt switch, the actuation of the two external electrodes pulls down the edges of the membrane and the switch goes on. When the two internal electrodes are actuated, the centre of the membrane pulls down and switch goes off. This structure allows combining low initial gap and large deflection of the membrane. The maximum deflection of the membrane is determined by the ratio of b/a Shown in Figure 1. The RF MEMS Switch with $360 \mu \mathrm{m}$ length of membrane and a gap of $1 \mu \mathrm{m}$ has a deflection of $1.8 \mu \mathrm{m}$ and actuation voltage of $3.5 \mathrm{v}$ for a ratio of 10 . It is obvious that there is a tradeoff between actuation voltage and maximum deflection. More deflection of membrane in shunt switches improves the RF characteristics reducing S11. This structure allows creating a design that improves the RF characteristics, reliability, and low actuation voltage. 
One effective method to decrease the actuation voltage is using the piezoelectric actuation [1][6][9][10]. Furthermore, piezoelectric switch technology has the ability to meet the high frequency requirement of low insertion loss, high isolation, high linearity, and low power consumption. Many researchers are focusing on this technology to make the actuation voltage lower and improve the RF characteristics. Concurrently, they try to increase the reliability which is needed for wireless commercial communication and military applications.

Another interesting design is reported in [1]. Dual beam of piezoelectric and symmetrical membranes were used (see Figure 2). This design managed to minimize the effect of the residual stress and variation of the initial air gap due to the fabrication process on the RF characteristic of the switches. Both beams of the switch actuated simultaneously with symmetrical voltages. Therefore, any change due to the effect of the residual stress is almost the same for both released cantilevers. The significant variation in the gap height does not happen which assures good reliability, lower actuation voltage ( 5 to $20 \mathrm{v}$ ) and faster switching time up to $2 \mu \mathrm{s}$. Furthermore, the DC and RF characteristics are insensitive to temperature variations.

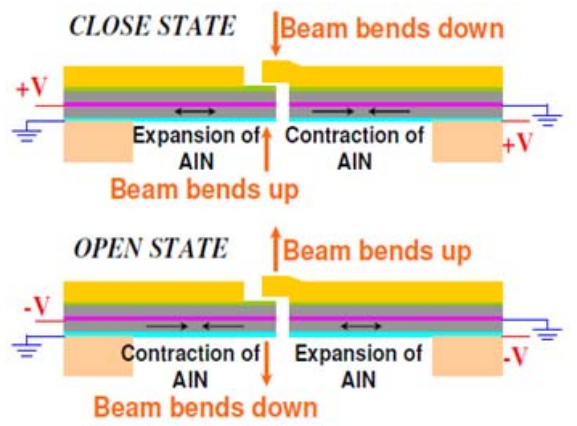

Figure 2. Schematic view of dual beam piezoelectric switch [1].

In spite of the excellent features, this design suffered from the large frequency band and the need for complicated process.

Seo et al. [11] presents lateral piezoelectric actuator with large lateral displacement. This design consists of PZT electrode layers which are located at the edge of the serpentine silicon spring as shown in Figure 3.

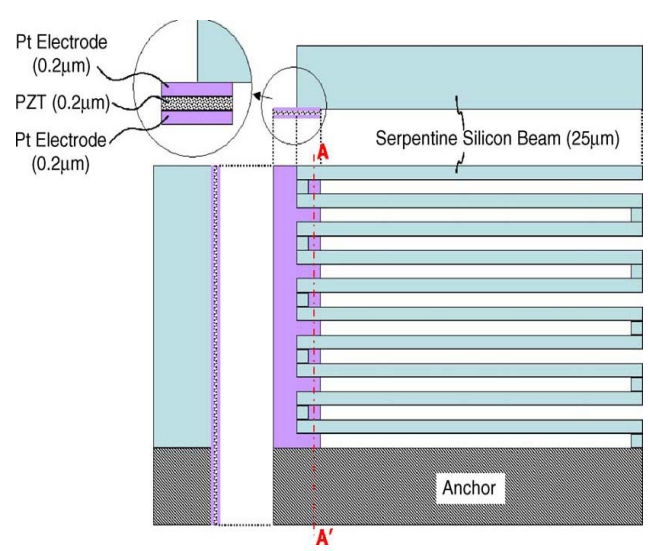

Figure 3. Lateral PZT actuator [11].
While the voltage is applied, the PZT layer is shrunk. Therefore, one side of the beam is compressed by the shrinkage motion of the PZT and the other side of the serpentine spread out. The aspect ratio (ratio of the beam height to beam width) of serpentine beam guides motion to large lateral displacement. From the simulation results for driving voltage of $10 \mathrm{v}$ dc, they found $16.1 \mu \mathrm{m}$ lateral displacements and only $0.55 \mu \mathrm{m}$ for vertical one. It means that this actuator generates lateral displacements much more than vertical displacements. The drawback of the switch is the complexity of the structure.

Fernandez-Bolanos et al. [12] proposed RF MEMS capacitive switch with low actuation voltage with excellent capacitive ratio close to 200, convenient for RF frequency (see Figure 4). This design uses low loss high resistivity silicon substrate. The measurement of scattering parameters of the switch shows an insertion loss of less than $0.5 \mathrm{~dB}$ and isolation more than $20 \mathrm{~dB}$ at $20 \mathrm{GHz}$ for an exciting pooling voltage of 8 v.

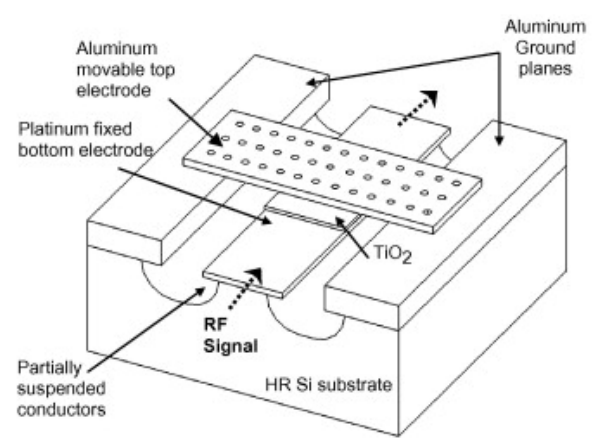

Figure 4. MEMS capacitive switch [12].

The disadvantage of this design is the lack of the reliability and life cycles which are caused by the very thin dielectric layer.

Kang et al. [13] proposed a sea saw type RF MEMS switch. They focused on improving the RF performance and actuation voltage simultaneously (see Figure 5). The electrostatic force between the combs is constant and does not vary with the gap height between the electrodes. In addition, the switch can be driven at lower voltages by decreasing the gap between the combs.

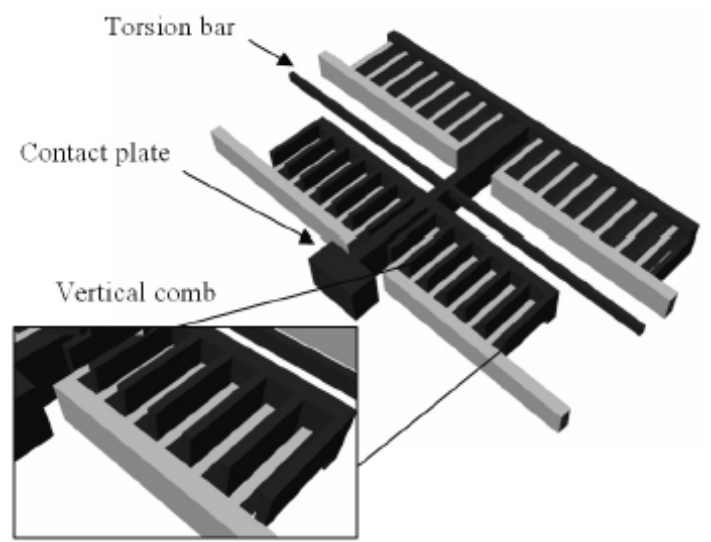

Figure 5. Sea saw type RF MEMS switch [13]. 
If the actuation voltage applied between the combs at the left side of the torsion bar, the left sides of the torsion bar moves downwards and the right side moves upward. Therefore, the switch goes on. If actuation voltages applied to the right side of the torsion bar, the switch goes to off. The switch was designed to actuate at $6 \mathrm{v}$ for wireless application. The gap between the contacts metal and transmission line is $5 \mu \mathrm{m}$. Thus, in off position the gap is $10 \mu \mathrm{m}$. The gap between the combs is $1.5 \mu \mathrm{m}$. The RF characteristics of the design switch were acceptable, the insertion loss up to $10 \mathrm{GHz}$ is less than $1 \mathrm{~dB}$ and isolation is more than $30 \mathrm{~dB}$ for the same band. The drawback of the switch is its fabrication. It needs fabrication of the bottom substrate and the body separately. Moreover, this design needs high accurate technology for the gap between the combs.

Cho et al. [14] propose a low power and low actuation voltage switch by the combination of electromagnetic and electrostatic forces with a latching mechanism. Switch actuates by a large electromagnetic force and is maintained by an electrostatic force of low voltage. Figure 6 shows the schematic diagram of the switch. This mechanism could be used for both of the shunt and series switches.
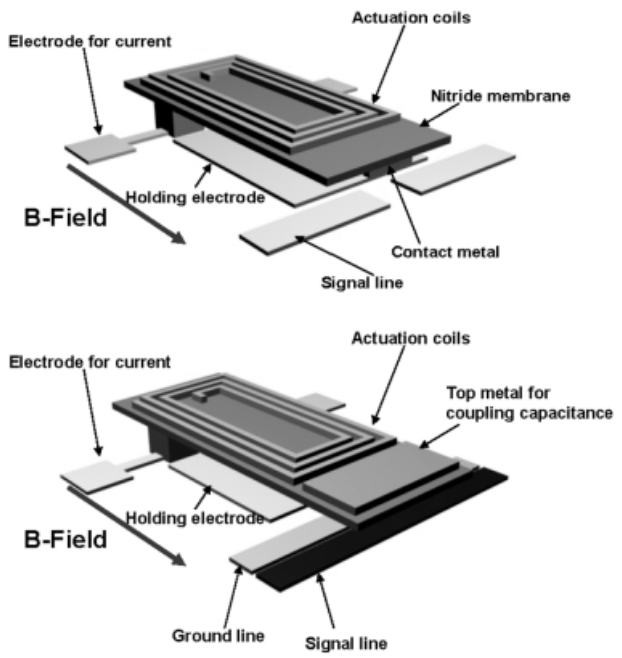

Figure 6. Schematic diagram of the combination of electromagnetic and electrostatic forces [14].

When a DC current is applied to coil in the counter clockwise direction, by Lorentz forces, the membrane is actuated to down position and contact the RF transmission line. At this moment, the weak electrostatic force between the coils and the bottom electrode hold the membrane. To return the membrane to up state the current should be applied to the coil by clockwise.

The electromagnetic force is constant regardless of the height of the membrane from the bottom transmission line. This allows the large initial gap and therefore excellent RF performance. In addition, operating voltage can be maintained bellow $5 \mathrm{v}$ because the electrostatic force is only applied during the holding state. The backward of this switch design is the need for relatively large power for electromagnetic actuation. Furthermore, it needs a large area for fabricating the coil.

\section{PROPOSED RF MEMS SWITCH}

The RF switches are the best alternatives for existing switches such as FET transistors, PIN diodes and coaxial cable switches. However, they still suffer from power handling and insertion loss ( $0.1 \mathrm{~dB}$ and more). Coaxial switches have almost zero $\mathrm{dB}$ insertion loss but they are heavy and costly [13]. Therefore, considerable investment has been directed toward the RF MEMS switches development.

\section{A. Working principle and theoretical desired values}

The proposed RF MEMS switch is comprised of an electro statically actuated shunt switch with two high impedance transmission lines at its input and output (see Figure 7).

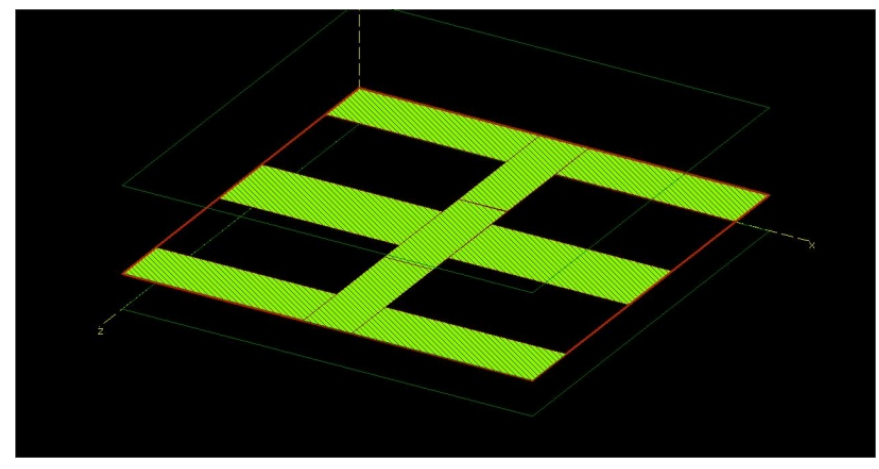

(a)

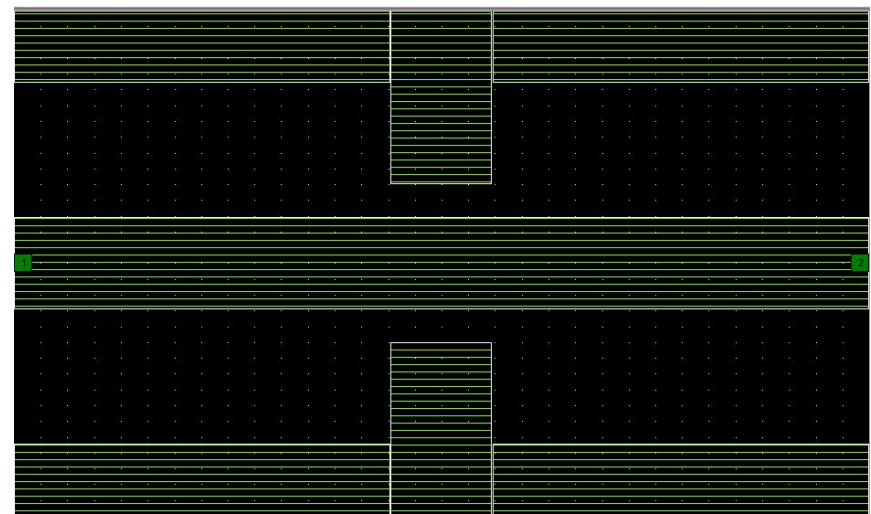

(b)

Figure 7. Proposed RF MEMS switch. (a) Switch. (b) Co planar waveguide.

In order to lower the actuation voltage, the following criteria are employed.

a) Decreasing the gap between membranes and signal line to $3.5 \mu \mathrm{m}$. The smaller value of the gap height leads to deterioration of the scattering parameters in RF waves in up state position.

b) Increasing the area of membrane before it becomes a prevailing issue. Rising the area of the membrane affects the RF characteristics of up state position.

c) Designing the shape of cantilever with low spring constant. 
d) Using two short high impedance transmission lines at the input and output of the switch. This design gives the opportunity for designer to makes the small gap.

Table I shows the desired values of the RF MEMS switch parameters.

TABLE I. DESIRED VALUE OF MEMS SWITCH PARAMETERS.

\begin{tabular}{|c|c|c|c|c|c|}
\hline $\begin{array}{c}\text { S11 } \\
\text { upstate }\end{array}$ & $\begin{array}{c}\text { S11 } \\
\text { downstat } \\
\text { e }\end{array}$ & $\begin{array}{c}\text { S21 } \\
\text { upstate }\end{array}$ & $\begin{array}{c}\text { S21 } \\
\text { downstat } \\
\text { e }\end{array}$ & $\begin{array}{c}\text { Frequen } \\
\text { cy }\end{array}$ & $\begin{array}{c}\text { Actuat } \\
\text { ion } \\
\text { voltage }\end{array}$ \\
\hline$<-10 \mathrm{~dB}$ & $>-0.5 \mathrm{~dB}$ & $<-0.5 \mathrm{~dB}$ & $<-20 \mathrm{~dB}$ & $40 \mathrm{GHz}$ & $<6 \mathrm{v}$ \\
\hline
\end{tabular}

\section{B. Design and simulation of the shunt switch}

Parallel switches initially in upstate is on and the state changes to off position when it is actuated. In upstate position, the switch should be matched with input and output circuits. Because of the small capacitance between the membrane and transmission line in upstate, there is not an ideal match specially at high frequency. Fig 7.a. The value of S11 (Equation1 ) increases with frequency.

$$
S 11=\frac{-2 w C_{u} Z_{0}}{1+2 j w C_{u} Z_{0}}
$$

For matching at the input, $\mathrm{S} 11$ should be less than $-10 \mathrm{~dB}$. For standard characteristic impedance $(\mathrm{Z0}=50 \Omega)$ at $40 \mathrm{GHz}$, the value of the upstate capacitor $\mathrm{C}_{\mathrm{u}}$ is $67 \mathrm{fF}$. $\mathrm{C}_{\mathrm{u}}$ of the low actuation voltage switches have reported between 20 to $115 \mathrm{fF}$ [1][12][15]-[17].

For small value of $\mathrm{Cu}$ the area of the membrane must be decreases and the height of the gap increased:

$$
\mathrm{C}_{\mathrm{u}}=\mathrm{k} \frac{\varepsilon A}{g+\frac{t d}{\varepsilon r}}
$$

In Equation (2), $\mathrm{k}$ represents the effect of fringing capacitance. In ideal capacitance $(\mathrm{k}=1)$, the fringing capacitance in upstate position between membrane and ground is comparable with ideal capacitance. $\mathrm{k}$ is mostly depends on gap height. For small value of $\mathrm{g}(<0.1 \mu \mathrm{m})$, the fringing capacitance is negligible and $\mathrm{k}=1$. For $\mathrm{g}=3.5 \mu \mathrm{m}, \mathrm{k}$ is calculated from the EM simulation is about 1.4. Using Equation 2, the effective area of the switching is $18900 \mu \mathrm{m}^{2}$. The length of the membrane for coplanar wave guide is $\mathrm{L}=$ $2 \mathrm{~W}+\mathrm{S}$ and width of the membrane can be easily calculated. $\left(\mathrm{W}_{\mathrm{m}}=139 \mu \mathrm{m}\right)$.

\section{Estimation of $Z_{h}$}

Characteristic impedance of short t-line $\left(Z_{h}\right)$ is a function of dimension of t-line, ht and $\varepsilon_{\mathrm{r}}$ of the substrate. By running the calculation program the optimized and proper value for $Z_{h}$ $=78 \Omega$. The $Z_{\mathrm{h}}$ Bigger than this value widening t-line excessively.
The switch with its t-line should be matched at the input and output $(\mathrm{S} 11=0)$. By equating $\mathrm{S} 11=0$, the short $\mathrm{t}$-line can be calculated:

$$
\tan (\beta l)=\frac{Z_{h}{ }^{2}-Z_{0}{ }^{2} \pm \sqrt{\left(Z_{h}{ }^{2}-Z_{0}{ }^{2}\right)^{2}-\omega^{2} C_{u}{ }^{2} Z_{h}{ }^{4} Z_{0}{ }^{2}}}{\omega C_{u} Z_{h}{ }^{3}}
$$

$\mathrm{Z}_{0}=50 \Omega$
$\mathrm{Z}_{\mathrm{h}}=78 \Omega$
$\mathrm{C}_{\mathrm{u}}=67 \mathrm{fF}$
$\omega=40 \mathrm{GHz}$
$1=0.515 \mathrm{~mm}$

As a transmission lines are too short, dissipation is negligible and the isolation of the switch match is insensitive to the length of the t-line.

\section{Simulation RESUlts}

The EM3DS software from MEM Research is used to calculate the Scattering parameters associated with the switch. Figures 8-11 show the scattering parameters for the switch with and without the short high impedance transmission line. The improvements of the scattering parameters are obvious. The simulation results for the frequency with short transmission lines are excellent ( $\mathrm{S} 11$ is $-50 \mathrm{~dB})$. However, this switch could work between 2 to $50 \mathrm{GHz}$ with $\mathrm{S} 11$ better than $-17 \mathrm{~dB}$.

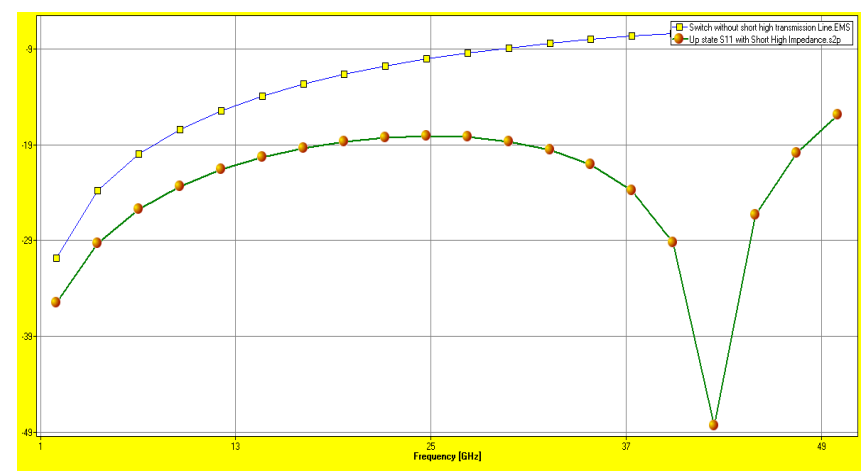

Figure 8. S11 upstate.

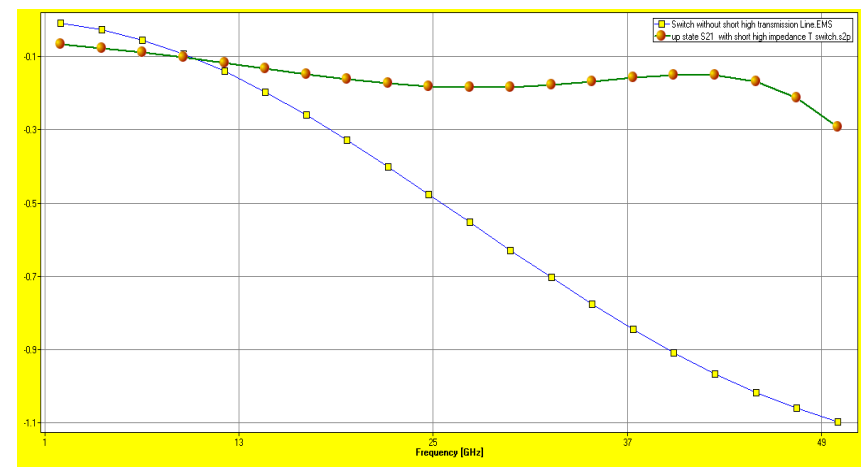

Figure 9. S21 upstate. 


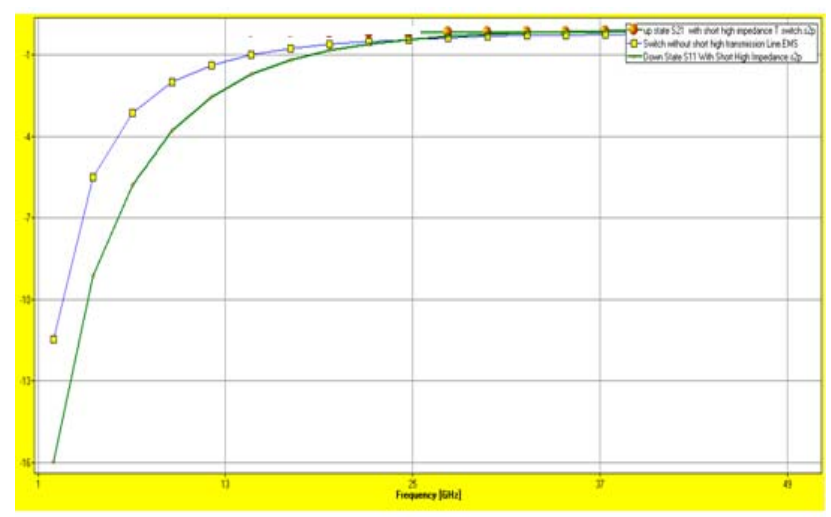

Figure 10. S11 downstate.

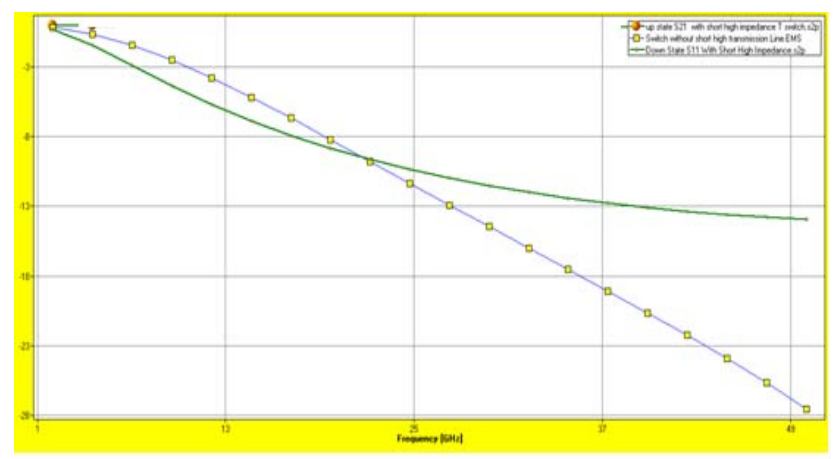

Figure 11. S21 downstate.

Moreover, S21 for the up state position is less than $0.3 \mathrm{~dB}$ at $50 \mathrm{GHz}$ comparing to without transmission lines which is $1.1 \mathrm{~dB}$. The results show that how the short transmission lines improve the characteristics of Scattering parameters at the upstate position.

Figures 10-11 show that the high impedance short lines do not have significant effects on the RF parameter at downstate position for the frequency of more than $25 \mathrm{GHz}$.

\section{CONCLUSIONS}

A RF MEMS capacitive coupling shunt switch has been proposed, designed and simulated. The electrostatic mechanism has been chosen for actuation. This mechanism is more popular and less costly than the other kind of switches which have been reviewed in this paper. Basically, design objective has been to obtain the minimum actuation voltage to make it usable in high frequency RF systems. Low actuation voltage can be achieved, partially by proper structure design of cantilever for minimum spring constant, decreasing the gap, and increasing the area of the membrane. Decreasing the gap and increasing the area enlarge the upstate capacitor $\mathrm{C}_{\mathrm{u}}$. The capacitor bypasses part of the RF signal to ground. Therefore the scattering parameters of the switch worsen. By integrating the specific short high impedance transmission line at the input and output of the switch, $\mathrm{C}_{\mathrm{u}}$ can be eliminated at the desired frequency. The scattering parameters are better than the estimated values for the very large frequency band from 25 to $50 \mathrm{GHz}$. The simulation results represent the utility of this short high impedance transmission line. It is expected that this method will lead to lowering the cost of the low voltage MEMS switches. Finally, it should be noted that the frequency band of the switch should be decreased. However, by optimizing the value of the length of the short transmission line, simulation results confirm the adequacy of the frequency band from $\mathrm{K}$ band to $\mathrm{V}$ band.

\section{ACKNOWLEDGMENT}

The authors wish to acknowledge the support Dr. Marco Farina, MEM Research, through the EM3DS software.

\section{REFERENCES}

[1] R. Mahameed, N. Sinha, M. Pisani, G. Piaza, "Dual Beam actuation of Piezoelectric A1N RF MEMS Switches Monolithically Integrated with A1N Contour-Mode Resonators," Journal of Micromechanics and Microengineering, 2008.

[2] G. Rebeiz, RF MEMS Theory, Design and Technology, New Jersey, J. Wiley, \& Sons, 2003.

[3] W. Moseley, E. M. Yeatman, A. S. Holmes, R. R. A. Syms, A. P. Finlay, P. Bonifac, "Silicon Low Power, Low Voltage MEMS Switches for Space Communication Systems," 19th IEEE International Conference, 2006.

[4] A. Stehle, C. Siegel, V Ziegler, B. Schonlinner, "High power handling capability of low complexity RF MEMS Switch in Ku band," Electronic Letters, IEEE Xplore, Vol. 43 No. 24, 22 November, 2007.

[5] J. Kusterer, E. Kohn, Luker, Kibry, "Diamond high speed and high power MEMS switches," 4th EMRS DTC Technical Conference, Edinburgh, 2007.

[6] H.-C. Lee, J.-Y. Park, J.-U. Bu, "Piezoelectrically actuated RF MEMS DC contact switches with low voltage operation," Microwave and Wireless Components Letters, IEEE, 2005.

[7] C. L. Goldsmith, D. I. Forehand, Z. Peng, J. C. M. Hwang, I. L. Ebel, "High-Cycle Life Testing of RF MEMS Switches," Microwave Symposium 1, 2007.

[8] S. Touati, N. Lorphelin, A. Kanciurzewski, R Robin, A. S. Rollier, O. Millet, K. Segueni, "Low Actuation voltage Totally free Flexible RF MEMS Switch With Antistiction Systems," DTIP, 2008.

[9] J. Park, H. Lee, J. Bu, "Low voltage Operated Piezoelectric RF MEMS Switches for Advanced handset Application," 34 European Microwave Conference, Amesterdam, 2004.

[10] H. Lee, J. Park, Y. Park, "Development of shunt type ohmic RF MEMS Switches actuated by piezoelectric cantilever," $25^{\text {th }}$ anniversary of Sensors and Actuators, 2007.

[11] Y. H. Seo, D. S. Choi, J. H. Lee, T. Jin, K. H. Whang, "Laterally driven thin film PZT actuator with high-aspect-ratio silicon beam for stroke amplification," $18^{\text {th }}$ International conference on Micro Electro Mechanical Systems, IEEE, 2005.

[12] M. Fernandez-Bolanos, J. Perruisseau, P. Diaesi, A. M. Ionescu, "RF MEMS capacitive switch on semi-suspended CPW using low-loss high resistivity silicon substrate," Micro and Nano Engineering conference, 2007.

[13] S. Kang, S. Moon, H. C. Kim, K. Chun, "See-saw Type RF MEMS switch with Narrow Gap vertical Comb," Journal of semiconductor technology and science, 2007.

[14] J. Cho, T. Song, S. Baek, E. Yoon, "A Low-Voltage and Low power RF MEMS Switch actuated by combination of Electromagnetic and Electrostatic Forces," $34^{\text {th }}$ European Microwave Conference, Amesterdam, 2004.

[15] F. Giacomozzi, "Development of High Con Coff Ratio RF MEMS Shunt Switches," Romanian Journal of information science and technology, 2008.

[16] C. Chen, D. Peroulis, "Electrostatic Liquid-Metal Capacitive Shunt Switch," IEEE, 2006.

[17] Z. Milosalvljevic, "RF MEMS switches," Mikrotalasna revija, 2004. 